\title{
ANALISIS KEPUASAN WISATAWAN PENGGUNA JASA TRANSPORTASI KOPERASI ANGKUTAN PARIWISATA SURYA KENCANA SANUR
}

\author{
Ni Komang Ayu Trisna Dewi ${ }^{1}$, I Ketut Suwena ${ }^{2}$, I Putu Sudana ${ }^{3}$ \\ ${ }^{1}$ Email : trisnadewi570@gmail.com \\ Program Studi S1 Industri Perjalanan Wisata, Fakultas Pariwisata, Universitas Udayana \\ 2Email : suwenaketut31@gmail.com \\ Program Studi S1 Industri Perjalanan Wisata, Fakultas Pariwisata, Universitas Udayana \\ ${ }^{3}$ Email : sudanaputu@yahoo.com \\ Program Studi S1 Industri Perjalanan Wisata, Fakultas Pariwisata, Universitas Udayana
}

\begin{abstract}
The aim of this research is to determine tourists' tourist satisfaction analysis of users of tourism transport cooperative services Surya Kencana Sanur. Data was collected using observation method, interview, questionnire, documentation, and literature study. Respondents were determined using purpose sampling method with 18 indicators, and total respondents involved were 108 individuals. Data were analyzed using quantitative descriptive analysis technique with Importance Performance Analysis (IPA) with Likert scale to determine each indicator's quadrant. Services dimension studied were tangibility, reliability, responsiveness, assurance, and empathy. He results of this research showed that the average of tangibility variable is $88,60 \%$ categorized as less satisfied, average of reliability variable is $92,84 \%$ categorized as highly satisfied, average of responsiveness variable is $89.13 \%$ categorized as less satisfied, average of assurance variable is $89.70 \%$ categorized as less satisfied, and average of empathy variable is $89.39 \%$ categorized as less satisfied. Overall total of appropriate level is $89.77 \%$. From this research, it is expected that the company improves services which are considered as important by tourists, but drivers' performances have not met tourists' expectation. Indicators which have fulfilled tourists' expectation need to be maintained.
\end{abstract}

Abstrak: Tujuan penelitian ini untuk mengetahui analisis kepuasan wisatawan pengguna jasa transportasi koperasi angkutan pariwisata Surya Kencana Sanur. Pengumpulan data menggunakan metode observasi, wawancara, kuesioner, dokumentasi, studi kepustakaan. Penentuan informan menggunakan metode puposive sampling dengan 18 indikator, jumlah responden yang digunakan sebanyak 108 orang. Analisis data menggunakan teknik deskriptif kuantitatif dengan IPA atau Importance Performance Analysis dengan skala likert untuk menentukan kuadran masing-masing indikator. Dimensi pelayanan yang diteliti yaitu tangible, reliability, responsiveness, assurance, dan empathy.Hasil penelitian menunjukkan bahwa rata-rata variabel bukti langsung sebesar 88,60 persen dengan kategori kurang puas, variabel keandalan rata-rata sebesar 92,84 persen dengan kategori sangat puas, rata-rata variabel daya tanggap sebesar 89,13 persen dengan kategori kurang puas, rata-rata variabel jaminan sebesar 89,70 persen dengan kategori kurang puas dan rata-rata variabel empati sebesar 89,39 persen dengan kategori kurang puas. Hasil keseluruhan tingkat kesesuaian sebesar $89,77 \%$. Dengan hasil penelitian ini diharapkan perusahaan mampu meningkatkan pelayanan yang dianggap sangat penting oleh wisatawan, namun kinerja driver kurang memenuhi harapan wisatawan. Dan indikator yang sudah memenuhi dan sesuai harapan wisatawan agar dipertahankan.

Keywords: tourist satifaction and transportation. 


\section{PENDAHULUAN}

Pariwisata merupakan salah satu sektor yang sangat diandalkan dalam pembangunan nasional karena dapat meningkatkan pendapatan nasional dan pendapatan daerah serta devisa negara. Pariwisata juga berperan menciptakan lapangan kerja dan mengurangi pengangguran, sekaligus menciptakan kesejahteraan masyarakat.

Bali merupakan salah satu provinsi yang ada di Indonesia, terkenal akan keindahan alam, aneka warisan sejarah budaya, serta terkenal dengan pulau Seribu Pura. Objek wisata yang ada di Bali merupakan kekayaan alam yang patut untuk dibanggakan. Setiap daerah di Bali memiliki keunikan, baik dari segi keindahan alamnya maupun adat istiadat sehingga menarik minat wisatawan mancanegara maupun nusantara untuk mengunjungi Bali. Hal ini dapat dilihat dari jumlah kunjungan wisatawan mancanegara ke Bali dalam kurun waktu 2012 -- 2016. Jumlah wisatawan macanegara dan domestik yang berkunjung ke Bali setiap tahun mengalami peningkatan. Penurunan terjadi pada tahun 2014, tetapi tidak terlalu signifikan, sedangkan pada tahun 2015 dan 2016 kunjungan wisatawan meningkat kembali. Diperkirakan bahwa peningkatan ini diakibatkan karena munculnya peraturan Presiden Nomor 104 tahun 2015 tentang peningkatan jumlah negara menjadi 90 negara yang mendapatkan fasilitas bebas ;visa kunjungan ke Indonesia (http://imigrasi.go.id). Ditahun 2016 muncul kembali peningkatan jumlah negara bebas visa kunjungan melalui peraturan Presiden No. 21 tahun 2016 mengenai penetapan 169 negara bebas visa. Adanya bebas visa kunjungan, membuat wisatawan mancanegara dapat melakukan kunjungan di Indonesia maksimal 30 hari. Oleh sebab itu, jumlah wisatawan mancanegara yang berkunjung ke Bali sejak peraturan itu dikeluarkan semakin meningkat. Bertambahnya kunjungan wisatawan ke Bali, maka penting adanya sarana dan prasarana pariwisata untuk menunjang kegiatan pariwisata.

Transportasi merupakan sarana pokok dalam pariwisata. Transportasi berarti mengangkut atau membawa (sesuatu) ke sebelah lain atau dari suatu tempat ke tempat lainnya. Ini berarti transportasi merupakan suatu jasa yang diberikan, guna menolong orang dan barang untuk dibawa dari suatu tempat ke tempat lainnya. Dengan demikian, transportasi sebagai usaha dan kegiatan mengangkut atau membawa barang dan/atau penumpang dari suatu tempat ke tempat lainnya. Jasa transportasi digunakan sebagai alat untuk memperoleh keuntungan-keuntungan ekonomis dalam berbagai kegiatan usaha dan hubungan kemasyarakatan (Kamaluddin, 2003:13).

Sektor transportasi merupakan salah satu komponen yang harus ada didalam industri pariwisata. Didalam melakukan suatu perjalanan wisata, wisatawan membutukan sarana transportasi baik transportasi darat, udara, maupun laut untuk memudahkan wisatawan yang akan pergi ke sebuah destinasi atau daerah tujuan wisatanya.

Dewasa ini, usaha transportasi tumbuh dan berkembang semakin pesat. Hal tersebut dikarenakan tingkat kebutuhan masyarakat atau wisatawan akan transportasi terus bertambah. Dapat dilihat dari banyaknya jenis usaha yang bergerak di bidang transportasi di berbagai daerah tujuan wisata di Indonesia. Hal ini menunjukkan bahwa bisnis transportasi merupakan bisnis yang cukup menjanjikan bagi para pengusaha dalam menjalankan usaha di bidang jasa transportasi. Namun, yang menjadi persoalan adalah bagaimana bisnis pelayanan jasa tersebut bisa menjadi sebuah usaha jasa yang maju dan berkembang serta disukai oleh wisatawan.

Pada prinsipnya, usaha transportasi merupakan salah satu usaha perdagangan yang bergerak dibidang jasa. Sebagai industri jasa setiap pengusaha transportasi akan berusaha untuk memberikan 
pelayanan yang maksimal kepada para penumpangnya. Dengan kata lain, kekuatan dari usaha ini adalah bagaimana pelaku usaha transportasi mampu memberikan jasa terbaik kepada para penumpangnya untuk meningkatkan kepuasan wisatawan terhadap kualitas pelayanan transportasinya. Wisatawan dikatakan puas apabila suatu jasa atau pelayanan yang diberikan kepada para penumpang atau pengguna jasa transportasi diberikan maksimal dan menyebabkan seseorang mempunyai alasan tersendiri memilih untuk kembali menggunakan jasa transportasi tersebut, dibandingkan dengan memilih jasa transportasi lainnya.

Sanur adalah suatu destinasi lokal yang menawarkan pantai yang indah. Pantai sanur sangat bagus untuk melihat sunrise atau matahari terbit karena pantai sanur menghadap ke Timur. Di pantai Sanur juga terdapat banyak industri hospitality. Salah satunya, hotel Grand Inna Bali Beach. Hotel ini merupakan hotel yang pertama kali dibangun di Sanur. Selain hotel, di Sanur juga terdapat banyak jasa transportasi. Hampir di setiap jalan terdapat orang-orang yang menjual jasa transportasi. Oleh karena itu, penting bagi pemilik jasa transportasi untuk meningkatkan kualitas pelayanan agar bisa meningkatkan kepuasan wisatawan yang menggunakan jasa transportasi tersebut, sehingga wisatawan kembali menggunakan jasa transportasinya.

Oliver (1980) mendefinisikan bahwa kepuasan adalah tingkat perasaan seseorang setelah membandingkan kinerja atau hasil yang dirasakan dengan harapan. Kepuasan konsumen merupakan tujuan dari berdirinya suatu usaha. Ini berarti kepuasan adalah tujuan utama suatu usaha karena apabila wisatawan puas maka usaha tersebut akan mendatangkan laba atau pendapatan bagi perusahaan. Menurut Philip Kotler (1994) untuk mengetahui kepuasan wisatawan dapat diketahui dari lima (5) aspek yaitu: Bukti Fisik (tangibles), Keandalan (realiability), Daya
Tanggap (responsiveness), Jaminan (assurance), dan Empati (empathy). Lima aspek tersebut sangat penting untuk ditingkatkan dan dikembangkan oleh perusahaan jasa transportasi.

Berkembangnya pariwisata di Sanur mengakibatkan banyak muncul transportasi di sekitar Sanur. Munculnya transportasi online menjadi saingan pasar jasa transportasi lokal. Hal tersebut menyebabkan turunya pangsa pasar dari transportasi lokal. Untuk itu, para penyedia jasa transportasi lokal harus benar-benar meningkatkan kualitas demi menjaga pangsa pasar. Penelitian ini diperlukan untuk mengetahui tingkat kepuasan wisatawan pengguna jasa transportasi koperasi angkutan pariwisata Surya Kencana Sanur.

\section{METODE PENELITIAN}

Penelitian ini dilakukan di desa Sanur, kecamatan Denpasar Selatan, kabupaten Denpasar. Terdapat lima variabel dalam penelitian ini yaitu: Bukti nyata ( tangible), Keandalan ( reliability), Daya tanggap ( responsiveness), Jaminan ( assurance ), Empati ( empathy ), dan terdapat 18 (delapan belas) indikator.

Pengumpulan data dilakukan dengan wawancara, teknik observasi yang digunakan peneliti adalah teknik non partisipan. Peneliti tidak terlibat langsung karena kuesioner disebarkan melalui driver. Jadi, peneliti akan menerima hasil kuesioner yang sudah diserbakan melalui driver. Studi kepustakaan, dan dokumentasi. Teknik penentuan sampel dilakukan dengan purposive sampling, yaitu sample berdasarkan ciri dan sifat tertentu yang ada sangkut paut dengan permasalahan sebagai informan kunci pada suatu golongan (Arikunto,1998). Artinya, sample yang diambil adalah wisatawan yang memiliki kriteria yaitu wisatawan yang menggunakan jasa transportasi Koperasi Angkutan Pariwisata Surya Kencana Sanur. Data diperoleh dari penyebaran 108 kuesioner kepada 
responden. Analisis data dilakukan dengan Importance Performance Analysis.

\section{HASIL}

Hasil penelitian tingkat kepentingan dan tingkat kinerja driver Koperasi Angkutan Pariwisata Surya Kencana Sanur, dihasilkan suatu perhitungan mengenai tingkat kesesuaian antara kepentingan dan kinerja. Dapat dilihat pada tabel di bawah:

Tabel tabulasi rata-rata perhitung kinerja dan penilaian kepentingan serta tingkat kesesuaian faktor mempengaruhi tingkat kepuasan wisatawan terhadap kualitas pelayanan jasa transportasi di koperasi angkutan pariwisata Surya Kencana Sanur.

\begin{tabular}{|c|c|c|c|c|c|c|}
\hline No & Indikator & $\begin{array}{c}\text { Slkor } \\
\text { penihian } \\
\text { linerja }\end{array}$ & $\begin{array}{c}\text { Skor } \\
\text { penilaia } \\
\text { n } \\
\text { kepenti } \\
\text { ngan }\end{array}$ & $\bar{X}$ & $\bar{Y}$ & $\begin{array}{c}\text { Tinglat } \\
\text { keesesuaian } \\
(96)\end{array}$ \\
\hline 1 & $\begin{array}{l}\text { Teayyamanan wisatawan } \\
\text { saat menggunnakan jasa } \\
\text { tansportasi. }\end{array}$ & 431 & 482 & 3,99 & 4,46 & 89,41 \\
\hline 2 & $\begin{array}{l}\text { Penampilan dan kerapian } \\
\text { drviver. }\end{array}$ & 437 & 472 & 4,04 & 4,37 & 92,58 \\
\hline 3 & $\begin{array}{l}\text { Kebersitan kendaaran dari } \\
\text { sisi, dalam dan luas. }\end{array}$ & 420 & 491 & 3,88 & 4,54 & 85,53 \\
\hline 4 & $\begin{array}{l}\text { Atribut kelengenkapan } \\
\text { berkendaraan sestuai } \\
\text { peranran }\end{array}$ & 431 & 496 & 3,99 & 4,59 & 86,89 \\
\hline 5 & $\begin{array}{l}\text { Penguasaan bahasa yang } \\
\text { konumilatif dari driver. }\end{array}$ & 422 & 444 & 3,90 & 4,11 & 95,04 \\
\hline 6 & $\begin{array}{l}\text { Driver sudah terlath } \\
\text { melayam wisatawan }\end{array}$ & 435 & 470 & 4,02 & 4,35 & 92,55 \\
\hline 7 & $\begin{array}{l}\text { Driver mengantarkan } \\
\text { wisatawan ke tempat tujuan } \\
\text { dengan tepat }\end{array}$ & 422 & 464 & 3,90 & 4,29 & 90,94 \\
\hline 8 & $\begin{array}{l}\text { Sikap menghargai } \\
\text { wisatawen dalam memberi } \\
\text { pelayanan }\end{array}$ & 432 & 470 & 4 & 4,35 & 91,91 \\
\hline 9 & $\begin{array}{l}\text { Kecepatan driver tba } \\
\text { ketika wissatawan memesan } \\
\text { tansportasi }\end{array}$ & 421 & 475 & 3,89 & 4,39 & 88,63 \\
\hline 10 & $\begin{array}{l}\text { Pelayaman yang ceppat dan } \\
\text { efisien }\end{array}$ & 419 & 481 & 3,87 & 4,45 & 87,11 \\
\hline 11 & $\begin{array}{l}\text { Ketanggapan diviver dalam } \\
\text { mengatasi masalar }\end{array}$ & 416 & 469 & 3,85 & 4,34 & 88,69 \\
\hline 12 & $\begin{array}{l}\text { Inisiatif drtiver dalam } \\
\text { membantu wistawann }\end{array}$ & 426 & 477 & 3,94 & 4,41 & 89,30 \\
\hline 13 & $\begin{array}{l}\text { Driver bersikas sopan dan } \\
\text { ramah saat melayani } \\
\text { wisatawan }\end{array}$ & 428 & 467 & 3,96 & 4,32 & 91,64 \\
\hline 14 & $\begin{array}{l}\text { Bertanggung jawab atas } \\
\text { keselamatan wisatawan }\end{array}$ & 441 & 486 & 4,08 & 4,5 & 90,74 \\
\hline 15 & $\begin{array}{l}\text { Reamanan saat wisatawan } \\
\text { melakulan tour }\end{array}$ & 425 & 490 & 3,93 & 4,53 & 86,73 \\
\hline 16 & $\begin{array}{l}\text { Perhatian driver terhadap } \\
\text { pertalysan wistawan }\end{array}$ & 426 & 487 & 3,94 & 4,50 & 87,47 \\
\hline 17 & $\begin{array}{l}\text { Perhatian arriver terhadap } \\
\text { keinginan dan leburulhan } \\
\text { wisatawan }\end{array}$ & 430 & 480 & 3,98 & 4,44 & 89,58 \\
\hline 18 & $\begin{array}{l}\text { Perhatian driver terhadap } \\
\text { keluhan wisatawan }\end{array}$ & 441 & 484 & 4,08 & 4,48 & 91,11 \\
\hline & ulah Skor Keseluruban & 7.703 & 8.585 & 72,62 & 79,42 & $1.615,85$ \\
\hline
\end{tabular}

Perhitungan rata-rata tingkat kinerja dan kepentingan seluruh indikator yang mempengaruhi kepuasan wisatawan yang menggunakan jasa transportasi Koperasi Angkutan Pariwisata Surya Kencana Sanur adalah sebagai berikut.
$\overline{\bar{X}}=\frac{\sum_{i=1}^{n} X i}{k}$

$\overline{\bar{X}}=\frac{\text { Jumlah keseluruhan rata-rata } \text { kinerja }}{k}$

$\overline{\bar{X}}=\frac{72,62}{18}$

$\overline{\bar{X}}=4,03$

$\overline{\bar{X}}=$ Rata - rata dari rata - rata kinerja

$\overline{\bar{Y}}=\frac{\sum_{i=1}^{n} y i}{k}$

$\overline{\bar{Y}}=\frac{79,42}{18}$

$\overline{\bar{Y}}=4,41$

$\overline{\bar{Y}}=$ Rata - rata dari rata - rata kepentingan

Berdasarkan perhitungan rumus di atas, hasil rata - rata tingkat kinerja dan kepentingan seluruh indikator yang mempengaruhi kepuasan menggunakan jasa transportasi koperasi angkutan pariwisata Surya Kencana Sanur untuk tingkat kinerja ( $\overline{\bar{X}}$ ) adalah sebesar 4,03 dan untuk tingkat kepentingan $(\overline{\bar{Y}})$ sebesar 4,41. Dengan demikian, diperoleh tingkat kepuasan wisatawan terhadap keseluruhan indikator menggunakan rumus sebagai berikut.

$$
\begin{aligned}
& T K i=\frac{\sum T K i}{K} \\
& T K i=\frac{\text { jumlah keseluruhan tingkat kesesuaian }}{\text { jumlah indikator }} \\
& T K i=\frac{1615,85}{18} \\
& T K i=89,77 \%
\end{aligned}
$$

Berdasarkan tabel di atas, rata-rata skor X dan Y untuk indikator bukti nyata ( Tangible) sebesar 3,97 dan 4,49 dengan tingkat kesesuaian sebesar $88,60 \%$, dengan kriteria kurang puas. Rata - rata 
skor X dan Y untuk indikator keandalan ( Reliability) sebesar 3,94, dan 4,25 dengan tingkat kesesuaian sebesar 92,84\% dengan kriteria sangat puas. Selanjutnya, untuk indikator daya tanggap (Responsiveness) rata - rata skor X dan Y sebesar 3,91 dan 4,38 dengan tingkat kesesuaian sebesar 89,13, dengan kriteria kurang puas. Pada indikator jaminan (Assurance) rata - rata skor X dan Y sebesar 3,99 dan 4,45 dengan tingkat kesesuaian sebesar 89,70, dengan kriteria kurang puas. Sedangkan untuk indikator empati (Emphaty) rata - rata skor $\mathrm{X}$ dan $\mathrm{Y}$ sebesar 4 dan 4,47 dengan tingkat kesesuaian sebesar 89,39, dengan kriteria kurang puas. Dengan demikian, dapat dikatakat wisatawan merasa kurang puas dengan pelayanan driver pada Koperasi Angkutan Pariwisata Surya Kencana Sanur. Untuk itu, pihak koperasi perlu meningkatkan kualitas pelayanan yang lebih baik pada setiap indikator.

\section{Importance Performance Analysis}

Importance Performance Analysis

(analsis derajat kepentingan-kinerja) digunakan untuk mengetahui faktor atau indikator dari tingkat kepuasan dan kualitas pelayanan Driver. Untuk dapat mengetahui faktor atau indikator tersebut dalam diagram Kartesius maka ditentukan terlebih dahulu dua buah titik $\mathrm{X}$ dan $\mathrm{Y}$ yang akan membentuk dua buah garis berpotong membatasi empat bagian dalam diagram Kartesius.

Perhitungan $\mathrm{X}$ merupakan rata-rata dari rata-rata skor tingkat kinerja seluruh indikator, ditentukan dengan rumus sebagai berikut.

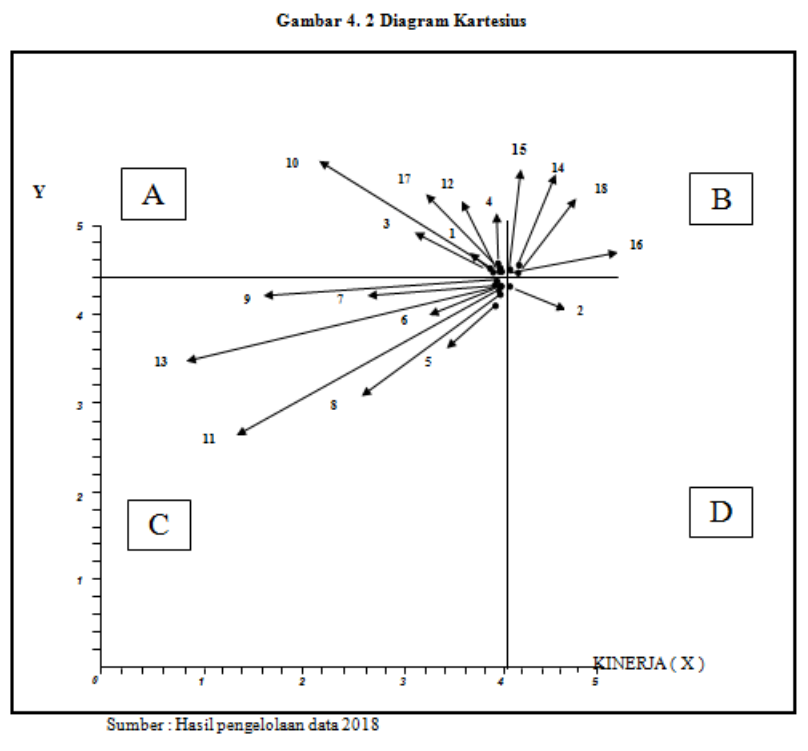

1. Kuadran A (Prioritas utama)

Kuadran A menunjukan faktor atau indikator yang mempengaruhi kepuasan wisatawan. Faktor atau indikator yang berada dalam kuadran ini perlu diprioritaskan oleh perusahaan karena indikator tersebut dianggap sangat penting oleh wisatawan. Sedangkan tingkat kinerja atau pelaksanaannya masih belum memuaskan. Adapun faktor atau indikator yang termasuk dalam kuadran ini adalah :

1) Kenyamanan wisatawan saat menggunakan jasa transportasi (1)

2) Kebersihan kendaaran dari sisi dalam, dan luar (3)

3) Atribut kelengkapan berkendaraan sesuai peraturan (4)

4) Pelayanan yang tepat dan efisien (10)

5) Inisiatif driver dalam membantu wisatawan (12)

6) Perhatian driver terhadap keinginan dan kebutuhan wisatawan (17)

2. Kuadran B (Pertahankan prestasi)

Kuadran B menunjukan faktor atau indikator yang mempengaruhi kepuasan wisatawan. Faktor atau indikator yang berada dalam kuadran ini dinilai perlu dipertahankan karena dianggap telah dengan baik dilaksanakan oleh driver serta tingkat kinerja atau pelaksanaannya sesuai dengan tingkat kepentingan dan 
harapan wisatawan. Adapun faktor atau indikator yang termasuk dalam kuadran ini adalah :

1) Bertanggung jawab atas keselamatan penumpang (14)

2) Keamanan saat wisatawan melakukan tour (15)

3) Perhatian driver terhadap pertanyaan dari wisatawan (16)

4) Perhatian driver terhadap keluhan wisatawan (18)

3. Kuadran C (Prioritas rendah)

Kuadran $\mathrm{C}$ menunjukan faktor atau indikator yang mempengaruhi kepuasan wisatawan. Faktor atau indikator yang berada dalam kuadran ini dinilai kurang penting oleh wisatawan, sedangkan kinerja atau pelaksanannya dinilai telah baik. Adapun faktor atau indikator yang termasuk dalam kuadran ini adalah :

1) Penguasaan bahasa yang komunikatif dari driver (5)

2) Driver sudah terlatih untuk melayani wisatawan ( 6 )

3) Driver mengantarkan wisatawan ketempat tujuan dengan tepat ( 7 )

4) Sikap menghargai wisatawan dalam memberikan pelayanan(8)

5) Kecepatan driver tiba ketika wisatawan memesan transportasi ( 9)

6) Ketanggapan driver dalam mengatasi masalah(11)

7) Driver bersikap sopan dan ramah pada saat melayani wisatawan (13)

\section{Kuadran D (Berlebihan)}

Kuadran D menunjukan faktor atau indikator yang mempengaruhi kepuasan wisatawan. Faktor atau indikator yang berada dalam kuadran ini dinilai pelaksanaannya berlebihan. Hal ini dikarenakan wisatawan menganggap kurang penting atau tidak penting, namun dilaksanakan dengan baik atau sangat baik oleh driver. Adapun faktor atau indikator yang termasuk dalam kuadran ini adalah : Penampilan dan kerapian driver ( 2 )

Untuk menentukan urutan prioritas pada indikator kualitas pelayanan jasa transportasi Koperasi Angkutan Pariwisata Surya Kencana Sanur, dilakukan dengan mengurutkan tingkat kesesuaian yang diperoleh. Semakin rendah tingkat kesesuaian yang diperoleh maka semakin tinggi prioritas indikator tersebut dan begitu pula sebaliknya. Semakin tinggi tingkat kesesuaian yang diperoleh maka semakin rendah prioritas indikator tersebut. Hasil penelitian ini dapat dilihat urutan prioritas indikator kualitas pelayanan jasa transportasi Koperasi Angkutan Pariwisata Surya Kencana Sanur pada tabel di bawah ini :

\begin{tabular}{|l|c|c|}
\hline \multicolumn{1}{|c|}{ Indikator } & $\begin{array}{c}\text { Tingkat } \\
\text { Kesesuaian }\end{array}$ & Prioritas \\
\hline Kebersihan kendaaran dari sisi, dalam, dan luar & $85,53 \%$ & 1 \\
\hline Keamanan saat wisatawan melakukan tour & $86,73 \%$ & 2 \\
\hline Atribut kelengkapan berkendaraan sesuai peraturan & $86,89 \%$ & 3 \\
\hline Pelayanan yang tepat dan efisien & $87,11 \%$ & 4 \\
\hline Perhatian driver terhadap pertanyaan wisatawan & $87,47 \%$ & 5 \\
\hline $\begin{array}{l}\text { Kecepatan driver tiba ketika wisatawan memesan } \\
\text { transportasi }\end{array}$ & $88,63 \%$ & 6 \\
\hline Ketanggapan driver dalam mengatasi masalah & $88,69 \%$ & 7 \\
\hline Inisiatif driver dalam membantu wisatawan & $89,30 \%$ & 8 \\
\hline $\begin{array}{l}\text { Kenyamanan wisatawan saat menggunakan jasa } \\
\text { transportasi }\end{array}$ & $89,41 \%$ & 9 \\
\hline $\begin{array}{l}\text { Perhatian driver terhadap keinginan dan kebutuhan } \\
\text { wisatawan }\end{array}$ & $89,58 \%$ & 10 \\
\hline Bertanggung jawab atas keselamatan penumpang & $90,74 \%$ & 11 \\
\hline $\begin{array}{l}\text { Driver mengantarkan wisatawan ke tempat tujuan } \\
\text { dengan tepat }\end{array}$ & $90,94 \%$ & 12 \\
\hline Perhatian driver terhadap keluhan wisatawan & $91,11 \%$ & 13 \\
\hline $\begin{array}{l}\text { Driver bersikap sopan dan ramah saat melayani } \\
\text { wisatawan }\end{array}$ & $91,11 \%$ & 14 \\
\hline $\begin{array}{l}\text { Sikap menghargai wisatawan dalam memberi } \\
\text { pelayanan }\end{array}$ & $91,91 \%$ & 15 \\
\hline Driver sudah terlatih untuk melayani wisatawan & $92,55 \%$ & 16 \\
\hline Penampilan dan kerapian driver & $92,58 \%$ & 17 \\
\hline Penguasan bahasa yang komunikatif dari driver & $95,04 \%$ & 18 \\
\hline
\end{tabular}

Dapat dilihat bahwa indikator kebersihan sisi dalam dan luar kendaaran merupakan indikator prioritas utama untuk ditingkatkan kualitas pelayanannya. Hal ini dapat dilihat dari tingkat kesesuaian yang diperoleh sebesar $85,53 \%$ merupakan tingkat kesesuaian terendah dari indikatorindikator lainnya. Sedangkan indikator yang memperoleh prioritas tertinggi adalah 
penguasaan bahasa yang komunikatif dari driver dengan tingkat kesesuain 95,04\%.

\section{SIMPULAN}

Berdasarkan hasil yang telah dipaparkan pada bab IV sebelumnya maka dapat disimpulkan analisis kepuasan wisatawan pengguna jasa transportasi koperasi Angkutan Pariwisata Surya Kencana Sanur sebesar 89,77\%. Artinya , secara keseluruhan wisatawan merasa puas mendapatkan pelayanan dari driver jasa koperasi angkutan Pariwisata Surya Kencana Sanur.

$\begin{array}{crr}\text { Berdasarkan } & \text { hasil tabulasi } \\ \text { perhitungan kinerja dan penilaian }\end{array}$
kepentingan dan tingkat kesesuaian variabel dapat disimpulkan bahwa pada variabel bukti langsung (tangible) indikator yang memiliki tingkat kesesuaian terendah yaitu kebersihan kendaraan dari sisi dalam dan luar sebesar 85,53\%. Artinya, driver harus memperhatikan kendaraannya agar selalu terlihat bersih dan wisatawan merasa nyaman saat perjalanan. Pada Variabel keandalan (reliability) indikator yang memiliki tingkat kesesuaian terendah yaitu driver mengantarkan wisatawan ke tempat tujuan dengan tepat sebesar 90,94 \% (persen). Artinya, driver harus lebih memperhatikan tujuan tour wisatawan agar tidak terjadi kesalahan sehingga tidak mengurangi kepuasan wisatawan. Pada variabel daya tanggap (responsiveness) indikator yang memiliki tingkat kesesuaian terendah yaitu pelayanan yang tepat dan efisien sebesar 87,11\% (persen). Artinya, wisatawan merasa kurang puas dengan pelayanan yang tepat dan efisien selama memakai jasa transportasi. Untuk itu penting bagi seluruh driver memberi pelayanan yang lebih bebas agar tidak mengurangi kepuasan wisatawan. Pada variabel jaminan (Assurance) indikantor yang memiliki tingkat kesesuaian terendah yaitu keamanan saat wisatawan melakukan tour sebesar 86,73\% (persen). Artinya, wisatawan merasa kurang nyaman dan aman dengan pelayanan yang diberikan driver. Pada variabel empati (emphaty) indikator yang memiliki tingkat kesesuaian terendah yaitu perhatian driver terhadap pertanyaan dari wisatwan sebesar 87,47 (persen). Artinya, driver harus menjawab pertanyan dengan sejelas-jelasnya agar wisatawan mendapat kepuasan.

\section{SARAN}

Berdasarkan hasil penelitian ini, maka dapat disampaikan saran khusus untuk driver Koperasi Angkutan Pariwisata Surya Kencana Sanur agar selalu menjaga kebersihan mobil dari sisi, luar, maupun dalam mobil, menjaga etika ketika bersama wisatawan, serta menjawab pertanyan wisatawan dengan benar. Diharapakan driver meningkatkan pelayanan sehingga kepuasan wisatawan dapat terpenuhi. 


\section{Kepustakaan}

Anonim, 1990. Undang-Undang Republik Indonesia Nomor 9 tahun 1990 tentang Kepariwisataan.

Anonim,2009. Undang-Undang Republik Indonesia No. 10 Tahun 2009 Tentang Kepariwisataan.

Arikuntoro,2002.Prosedur Penelitian. Jakarta: Renika Cipta

Budiartha RM, Nyoman, Adnyana, Ida Bagus Putu, 2016 "The Development of Marine Transportation System in Supporting Sustainable Tourism Case Study: Nusa Penida Island, Bali Indonesia". Journal of Sustainable Development; Vol. 9, No. 4.

Gasperz, V. 2005. Lean Sigma Approach. Jakarta: Penerbit Erlangga.

Hasan, Iqbal. 2002. Pokok - Pokok Materi Metodologi Penelitian dan Aplikasinya. Jakarta : Ghalia Indonesia.

Kamaluddin 2003. Ekonomi Transportasi. Jakarta: Ghalia Indonesia

Karana, Sjafril, Cahyo, Andi "Keberadaan Sarana Dan Prasarana Transportasi Dalam Industri Pariwisata Di Kepulauan Anambas". Direktorat Pengkajian Teknologi Rekayasa Industri Maritim.

Kotler, P. 2000. Marketin Management. Millenium. Edition. NJ: Pearson.

Kusmayadi,I.R. \& Sugiarto. 2000. Metodologi Penelitian dalam Bidang Kepariwisataan. Jakarta: PT.Gramedia Pustaka Utama.

Liu, Xiaoming, Li, Jun (Justin), Kim, Woo Gon, 2015."The role of travel experience in the structural relationships among tourists' perceived image, satisfaction, and behavioral intentions". Journal Tourism and Hospitality Reasearch.

Margono. 2003. Metode Penelitian Pendidikan. Jakarta: PT Asdi Mahasatya.

Miro, F. 2005. Perencanaan Transportasi untuk Mahasiswa, Perencana, dan Praktisi. Erlangga. Jakarta.
Nazir, Moh . 2005. Metode Penelitian. Jakarta: Ghalia Indonesia.

Parasuraman, A., Valarie A. Zeithaml, and Leonard L. Berry. 1985." A Conseptual Model of Service Quality and Its Implication for Future Research". Journal of Marketing, Vol. 49 (Fall).

Pendit. Nyoman S. 2002. Ilmu Pariwisata Sebuah Pengantar Perdana. Jakarta: PT. Pradnya Paramita.

Pitana,Gede.2005.Sosiologi

Pariwisata.Jakarta: Pradnya Paramita

Pitana, I Gde. dan Surya Diarta, I Ketut. 2009. Pengantar Ilmu Pariwisata. Yogyakarta : Penerbit Andi.

Purwoko. B. A. 2000. Kepuasan danLoyalitas: Perspektif Kualitas Layanan. Jakarta: Komunika JayaPratama.

Rambat Lupiyoadi. (2001). Manajemen Pemasaran Jasa (Teori dan Praktek). Edisi Pertama. Depok: Penerbit Salemba Empat.

Siboro, Surya, Millanyani, Heppy. "Customer Satisfaction Analysis Using Importance Performance Analysis (Case Study on Dealer Service Centers Anugrah Motor workshop in Bandung Soang Bojong Canal)". Jurnal Manajemen Bisnis Telekomunikasi dan Informatika.

Soebiyantoro, Ugy "Pengaruh Ketersediaan Sarana Prasarana, Sarana Transportasi Terhadap Kepuasan Wisatawan". Jurnal Manajemen Pemasaran, Vol. 4, No. 1, April 2009: 16-22.

Soekadijo. 2000. Anatomi Pariwista. Jakarta : Gramedia.

Suardana, I Wayan, Suwena, I Ketut, Leli Kusuma Dewi, Luh Gede "Tingkat Kepuasan Wisatawan Terhadap Kualitas Pelayanan Shuttle Bus Komotra Bali Di Central Park Kuta". Jurnal IPTA Vol.1 NO.1, 2013.

Sugiyono. 2007. Metode Penelitian Kuantitatif Kualitatif dan R\&D. Bandung: Alfabeta. 
Sunarto. 2003. Perilaku Konsumen. Yogyakarta: AMUS Yogyakarta dan CV. Ngeksigondo Utama.

Supranto,J.2006.Pengukuran Tingkat Kepuasan Pelanggan.Jakarta: PT.Rineka

Suwardi, Utomo, Joko. Analisis Manajemen vol. 5, no. 1, 2011:81.

Suwena, I Ketut dan Widyatmaja, Ngr I Gst. 2017. Pengetahuan Dasar Ilmu Pariwisata. Denpasar : Pustaka Larasan.

Tjiptono, Fandy. 2004. Manajemen Jasa, Edisi Kedua. Yogyakarta : Penerbit ANDI.

Tjiptono, F. 2012. Service Management: Mewujudkan Layanan Prima.Yogyakarta: Penerbit Andi.

Tse dan Wilton. 1988. Kepuasan Pelanggan, jilid 2. Edisi ketiga. Klaten : PT. Indeks Kelompok Gramedia.

Wirajaya, Yessy ". Analisis Kepuasan Wisatawan Mancanegara Terhadap Kualitas Pelayanan Pariwisata". Jurnal Manajemen dan Akuntansi. Volume 2, Nomor 3, Desember 2013.

Yoeti, Oka. A Edisi Revisi 1996, Pengantar Ilmu Pariwisata. Bandung: Penerbit Angkasa. 